\title{
Insights from tissue-specific transcriptome sequencing analysis of Triatoma infestans
}

\author{
Leilane O Gonçalves ${ }^{1,2}$, Luciana M de Oliveira ${ }^{1,3}$, Grasielle C D'Ávila Pessoa ${ }^{4}$, \\ Aline CL Rosa ${ }^{4}$, Marinely G Bustamante ${ }^{4}$, Carlota J Belisário ${ }^{4}$, \\ Daniela M Resende ${ }^{1,5}$, Lileia G Diotaiuti ${ }^{4}$, Jeronimo C Ruiz ${ }^{1 /+}$
}

\author{
1Fundação Oswaldo Cruz-Fiocruz, Centro de Pesquisas René Rachou, \\ Grupo Informática de Biossistemas e Genômica, Belo Horizonte, MG, Brasil \\ ${ }^{2}$ Fundação Oswaldo Cruz-Fiocruz, Centro de Pesquisas René Rachou, \\ Programa de Pós-Graduação em Ciências da Saúde, Belo Horizonte, MG, Brasil \\ ${ }^{3}$ Universidade Federal de Minas Gerais, Instituto de Ciências Biológicas, \\ Programa de Pós-Graduação em Bioinformática, Belo Horizonte, MG, Brasil \\ ${ }^{4}$ Fundação Oswaldo Cruz-Fiocruz, Centro de Pesquisas René Rachou, \\ Laboratório de Triatomíneos e Epidemiologia da Doença de Chagas, Belo Horizonte, MG, Brasil \\ ${ }^{5}$ Fundação Oswaldo Cruz-Fiocruz, Instituto Oswaldo Cruz, \\ Programa de Pós-Graduação em Biologia Computacional e Sistemas, Rio de Janeiro, RJ, Brasil
}

Triatoma infestans is an insect of subfamily Triatominae (Hemiptera: Reduviidae) and an important vector of Trypanosoma cruzi, the etiologic agent of human Chagas disease. In this work we reported a transcriptome assembly and annotation of T. infestans heads obtained by Next Generation Sequencing (NGS) technologies.

Key words: Next Generation Sequencing - Triatoma infestans - transcriptome assembly

Triatoma infestans is one of the vectors of Trypanosoma cruzi, the etiologic agent of human Chagas disease in South America. It's estimated that about 6-8 million people, mostly in Latin America, are infected worldwide and approximately 10,000 deaths per year were reported (Medone et al. 2015). T. infestans has high anthropophily, high colonisation capacity and high rates of infection. Because of these features, this triatominae is the main vector in the countries where it occurs, Bolivia, Argentina and Paraguay (Silveira 2002, Coura \& Dias 2009), where $T$. infestans populations that are resistant to pyrethroid insecticides have been a problem for the Chagas disease control (Vassena \& Picollo 2003, Audino et al. 2004, Picollo et al. 2005, Toloza et al. 2008, Germano et al. 2010, Lardeux et al. 2010, Gomez et al. 2015). In order to obtain the transcriptional profile of $T$. infestans, a total of seven samples from two Bolivian populations (Chaco and Bolivian Valley) were used. Each sample was a pool of twenty heads from nymphs on the third instar and was sequenced separately. Heads were chosen with the intention of obtaining transcripts that could be related to the neurotoxicity of the insecticides. The RNA was extracted using TRIzol@ Reagent kit (Invitrogen) and measured in Nanodrop ${ }^{\circledR}$ (Invitrogen). To the cDNA synthesis it was used $50 \mu \mathrm{g}$ of RNA. The sequencing of the paired end

doi: 10.1590/0074-02760160473

Financial support: CAPES, CNPq (307639/2004-5, 301526/2015-0 and 486618/2013-7), FAPEMIG (APQ-02375-13 and PPM-00710-15), CPqRR (no 401990/2012-5).

LOG, LMO, LGD and JCR contributed equally to this work.

+ Corresponding author: jeronimo@cpqrr.fiocruz.br

Received 27 October 2016

Accepted 2 February 2017
mRNA enriched libraries was performed on Illumina MiSeq platform. A total of 11,731,170 reads were generated, and the quality control was performed with PRINSEQ (Schmieder \& Edwards 2011). Data filtering and trimming was performed with Trimmomatic (Bolger et al. 2014). Sequence artifacts such as sequencing adapters were removed using data available at Trimmomatic software package. Using a cutoff of Phred quality $\geq 25$ and a minimum read length of $100 \mathrm{bp}$, a total of 10,335,132 reads from all samples were assembled together using Trinity (Haas et al. 2013) and for reduce the transcripts redundancy Cap3 (Huang \& Madan 1999) was also applied. The detailed information about de novo transcriptome assembly is reported in Table. The Trinity package identified a total of 65,043 transcripts with a median length of $313 \mathrm{bp}$ and a $\mathrm{N}_{50}$ value of 466 .

The functional annotation was performed using BLAST (Altschul et al. 1990) searching tool against non-redundant (NR) protein from NCBI and Swiss-Prot databases. The functional annotation results revealed that $58 \%$ and $72 \%$ of the proteins presented no hits to known sequences in the NR and Swiss-Prot databases, respectively. Regarding the NR comparison, among the proteins assigned with biological functions, $\sim 38 \%$ (9,111 proteins) have high sequence similarity $(\geq 70 \%)$ with Cimex lectularius and $\sim 23 \%$ (5,390 proteins) with Halyomorpha halys. Only $275(\sim 1 \%)$ proteins could be assigned for Triatoma spp and $163(\sim 0.7 \%)$ proteins to Rhodnius prolixus. None of the transcripts obtained was related to the cytotoxicity of pyrethroid insecticides.

Summarising, this work has the potential to contribute to a better understanding of the transcriptional profile linked with one of the most important vectors of the etiologic agent of human Chagas disease, $T$. infestans. 
TABLE

Summary of transcriptome assembly

\begin{tabular}{lc}
\hline Total of Trinity 'genes' & 62,449 \\
Total of Trinity transcripts & 65,043 \\
$\mathrm{G}+\mathrm{C}$ content & $36,59 \%$ \\
$\mathrm{~N}_{50}$ & 466 \\
Median contig length & $313 \mathrm{bp}$ \\
Total of Cap3 contigs & 5,219 \\
Total of Cap3 singlets & 50,680 \\
\hline
\end{tabular}

Accession codes - The BioProject accession number is PRJNA348445. The data used in this project has been deposited at SRA under the accession numbers SRR4427078, SRR4427079, SRR4449814, SRR4449815, SRR4449939, SRR4449940, SRR4449941 and BioSamples codes: SAMN05908558 and SAMN05908559.

\section{AUTHORS' CONTRIBUTION}

GCDP, ACLR, MGB, CJB and LGD - Conceived and designed the experiments; LOG, LMO, DMR and JCR - conceived and designed the bioinformatics analyses; LOG and LMO - analysed the data; LOG, LMO and CJB - wrote the paper; JCR, DMR and LGD - revised the paper final version.

\section{REFERENCES}

Altschul SF, Gish W, Miller W, Myers EW, Lipman DJ. Basic local alignment search tool. J Mol Biol. 1990; 215(3): 403-10.

Audino PG, Vassena C, Barrios S, Zerba E, Picollo MI. Role of enhanced detoxication in a deltamethrin-resistant population of Triatoma infestans (Hemiptera, Reduviidae) from Argentina. Mem Inst Oswaldo Cruz. 2004; 99(3): 335-9.

Bolger AM, Lohse M, Usadel B. Trimmomatic: a flexible trimmer for Illumina sequence data. Bioinformatics. 2014; 30(15): 2114-20.

Coura JR, Dias JCP. Epidemiology, control and surveillance of Chagas disease - 100 years after its discovery. Mem Inst Oswaldo Cruz. 2009; 104(Suppl. 1): 31-40.
Germano MD, Acevedo GR, Cueto GAM, Toloza AC, Vassena CV, Picollo MI. New findings of insecticide resistance in Triatoma infestans (Heteroptera: Reduviidae) from the Gran Chaco. J Med Entomol. 2010; 47(6): 1077-81.

Gomez MB, Pessoa GDC, Rosa ACL, Echeverria JE, Diotaiuti LG. Inheritance and heritability of deltamethrin resistance under laboratory conditions of Triatoma infestans from Bolivia. Parasit Vectors. 2015; 16; 8: 595.

Haas BJ, Papanicolaou A, Yassour M, Grabherr M, Blood PD, Bowden J, et al. De novo transcript sequence reconstruction from RNA-seq using the Trinity platform for reference generation and analysis. Nat Protoc. 2013; 8(8): 1494-512.

Huang X, Madan A. CAP3: a DNA sequence assembly program. Genome Res. 1999; 9(9): 868-77.

Lardeux F, Depickère S, Duchon S, Chavez T. Insecticide resistance of Triatoma infestans (Hemiptera, Reduviidae) vector of Chagas disease in Bolivia. Trop Med Int Health. 2010; 15(9): 1037-48.

Medone P, Balsalobre A, Rabinovich JE, Marti GA, Menu F. Life history traits and demographic parameters of Triatoma infestans (Hemiptera: Reduviidae) fed on human blood. J Med Entomol. 2015; 52(6): 1282-90.

Picollo MI, Vassena C, Orihuela PS, Barrios S, Zaidemberg M, Zerba E. High resistance to pyrethroid insecticides associated with ineffective field treatments in Triatoma infestans (Hemiptera: Reduviidae) from Northern Argentina. J Med Entomol. 2005; 42(4): 637-42.

Schmieder R, Edwards R. Quality control and preprocessing of metagenomic datasets. Bioinformatics. 2011; 27(6): 863-4.

Silveira AC. El control de la enfermedad de Chagas em los países del Cono Sur de América: historia de una iniciativa internacional 1991/2001. OMS; 2002. 316 pp.

Toloza AC, Germano M, Cueto GM, Vassena C, Zerba E, Picollo MI. Differential patterns of insecticide resistance in eggs and first instars of Triatoma infestans (Hemiptera: Reduviidae) from Argentina and Bolivia. J Med Entomol. 2008; 45(3): 421-6.

Vassena CV, Picollo MI. Monitoreo de resistencia a insecticidas en poblaciones de campo de Triatoma infestans y Rhodnius prolixus, insectos vectores de la Enfermedad de Chagas. RETEL. 2003; 3: 21. 